\title{
Comparison of RADIo PROPAgation MODElS FOR LONG TERM EVOLUTION (LTE) NETWORK
}

\author{
Noman Shabbir ${ }^{1}$, Muhammad T. Sadiq ${ }^{2}$, Hasnain Kashif ${ }^{3}$ and Rizwan Ullah ${ }^{4}$ \\ ${ }^{1}$ Department of Electrical Engineering, GC University, \\ Lahore, Pakistan \\ noman. shabbir@gcu. edu.pk \\ ${ }^{2}$ Department of Electrical Engineering, Blekinge Institute of Tech., \\ Karlskrona, Sweden \\ mtsa09abth.se \\ ${ }^{3}$ Department of Electrical Engineering, COMSATS Institute of IT, \\ Attock, Pakistan \\ ${ }^{4}$ Department of Electrical Engineering, COMSATS Institute of IT, \\ Attock, Pakistan \\ rizwan_ullahecomsats.edu.pk
}

\begin{abstract}
This paper concerns about the radio propagation models used for the upcoming $4^{\text {th }}$ Generation (4G) of cellular networks known as Long Term Evolution (LTE). The radio wave propagation model or path loss model plays a very significant role in planning of any wireless communication systems. In this paper, a comparison is made between different proposed radio propagation models that would be used for LTE, like Stanford University Interim (SUI) model, Okumura model, Hata COST 231 model, COST Walfisch-Ikegami \& Ericsson 9999 model. The comparison is made using different terrains e.g. urban, suburban and rural area.SUI model shows the lowest path lost in all the terrains while COST 231 Hata model illustrates highest path loss in urban area and COST Walfisch-Ikegami model has highest path loss for suburban and rural environments.
\end{abstract}

\section{KEYWORDS}

Long Term Evolution, LTE, Path loss, Propagation models.

\section{INTRODUCTION}

Long Term Evolution (LTE) is the latest step in moving forward from the cellular $3^{\text {rd }}$ Generation $(3 \mathrm{G})$ to $4^{\text {th }}$ Generation $(4 \mathrm{G})$ services. LTE is often described as a $4 \mathrm{G}$ service but it is not fully compatible to $4 \mathrm{G}$ standards. An improved version of LTE known as LTE advance is a $4 \mathrm{G}$ compatible technology. Both LTE \& LTE advance uses the same frequency band. LTE is based on standards developed by the 3rd Generation Partnership Project (3GPP). LTE may also be referred more formally as Evolved UMTS Terrestrial Radio Access (E-UTRA) and Evolved UMTS Terrestrial Radio Access Network (E-UTRAN). Even though 3GPP created the standards for family, the LTE standards are completely new with exceptions where it made sense. 
The following are the main objectives for LTE [1].

- Increased downlink and uplink peak data rates

- Scalable bandwidth

- Improved spectral efficiency

- All IP network

- A standard's based interface that can support a multitude of user types

LTE will be having a downlink speed of $100 \mathrm{Mbps}$ and an uplink of almost $50 \mathrm{Mbps}$. The channel will be having a scalable bandwidth from $1 \mathrm{MHz}$ to $20 \mathrm{MHz}$ while supporting both Frequency Division Duplex (FDD) and Time Division Duplex (TDD) [1]. These data rates can be further increased by employing multiple antennas both at the transmitter and receiver.

The selection of a suitable radio propagation model for LTE is of great importance. A radio propagation model describes the behavior of the signal while it is transmitted from the transmitter towards the receiver. It gives a relation between the distance of transmitter \& receiver and the path loss. From this relation, one can get an idea about the allowed path loss and the maximum cell range. Path loss depends on the condition of environment (urban, rural, dense urban, suburban, open, forest, sea etc), operating frequency, atmospheric conditions, indoor/outdoor \& the distance between the transmitter \& receiver.

In this paper, a comparison is made between different radio propagation models in different terrains to find out the model having least path loss in a particular terrain and which has the highest.

\section{RADIO PROPAGTION MODELS}

\subsection{SUI Model}

Stanford University Interim (SUI) model is developed for IEEE 802.16 by Stanford University [2], [3]. It is used for frequencies above $1900 \mathrm{MHz}$. In this propagation model, three different types of terrains or areas are considered. These are called as terrain A, B and C. Terrain A represents an area with highest path loss, it can be a very dense populated region while terrain $\mathrm{B}$ represents an area with moderate path loss, a suburban environment. Terrain $\mathrm{C}$ has the least path loss which describes a rural or flat area. In Table 1, these different terrains and different factors used in SUI model are described.

Table 1: Different terrains \& their parameters

\begin{tabular}{|c|c|c|c|}
\hline Parameters & Terrain A & Terrain B & Terrain C \\
\hline $\mathrm{a}$ & 4.6 & 4 & 3.6 \\
\hline $\mathrm{b}(1 / \mathrm{m})$ & 0.0075 & 0.0065 & 0.005 \\
\hline $\mathrm{c}(\mathrm{m})$ & 12.6 & 17.1 & 20 \\
\hline
\end{tabular}

The path loss in SUI model can be described as

$$
P L=A+10 Y \log \left(\frac{d}{d_{o}}\right)+X_{f}+X_{h}+5
$$

where $P L$ represents Path Loss in $\mathrm{dBs}, d$ is the distance between the transmitter and receiver, $d_{o}$ is the reference distance (Here its value is 100), $X_{f}$ is the frequency correction factor, $X_{h}$ is the 
Correction factor for BS height, $S$ is shadowing $\& y$ is the path loss component and it is described as

$$
Y-a-b h_{b}+\frac{c}{h_{b}}
$$

where $h_{b}$ is the height of the base station and $a, b$ and $c$ represent the terrain for which the values are selected from the above table.

$$
A=20 \log \left(\frac{4 \pi d_{e}}{\lambda}\right)
$$

where $A$ is free space path loss while $d_{o}$ is the distance between Tx and $\operatorname{Rx}$ and $\lambda$ is the wavelength. The correction factor for frequency $\&$ base station height are as follows:

$$
\begin{aligned}
& X_{f}=6 \log \left(\frac{f}{2000}\right) \\
& X_{h}=-10.8 \log \left(\frac{h_{r}}{2000}\right)
\end{aligned}
$$

where $f$ is the frequency in $\mathrm{MHz}$, and $h_{r}$ is the height of the receiver antenna. This expression is used for terrain type A and B. For terrain C, the blow expression is used.

$$
\begin{aligned}
& X_{h}=-20 \log \left(\frac{h_{r}}{2000}\right) \\
& S=0.65(\log f)^{2}-1.3 \log (f)+\alpha
\end{aligned}
$$

Here, $\alpha=5.2 \mathrm{~dB}$ for rural and suburban environments (Terrain A \& B) and $6.6 \mathrm{~dB}$ for urban environment (Terrain C).
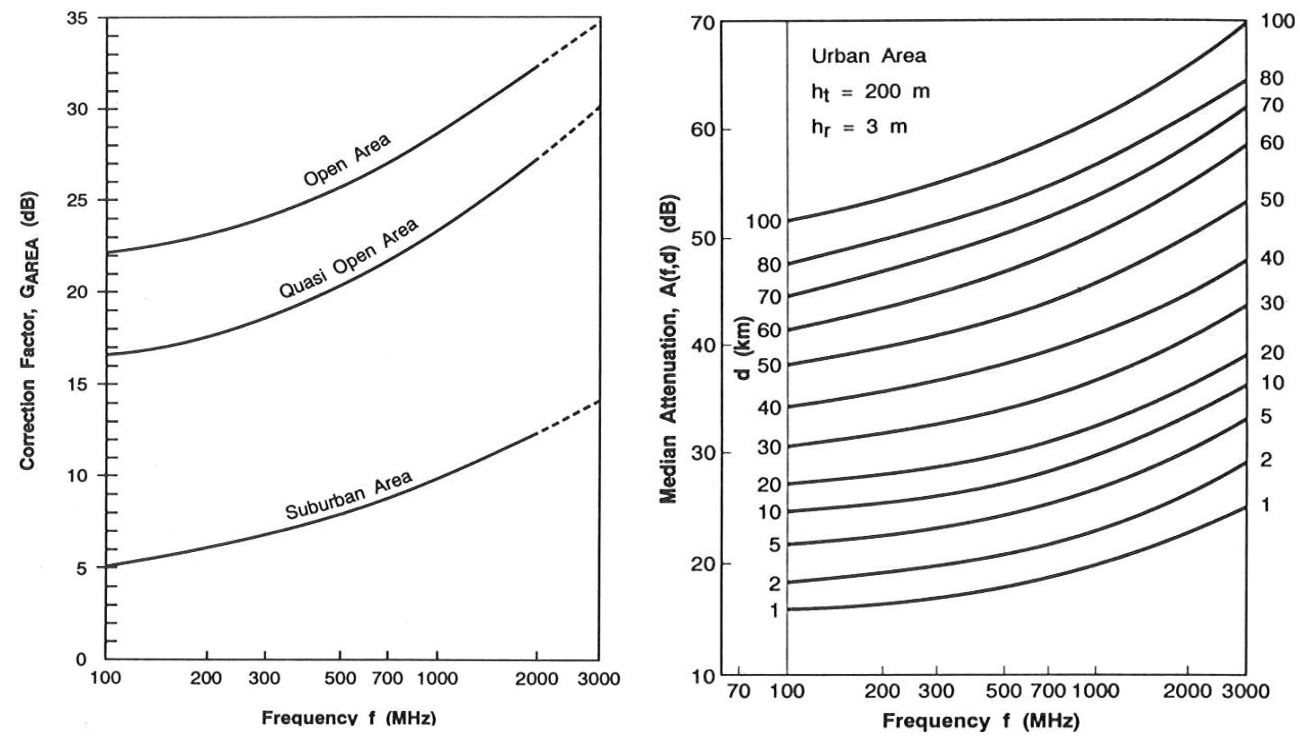

Figure 1: Median attenuation factor for Okumura Model 


\subsection{Okumura Model}

Okumura model [4], [9] is one of the most commonly used models. Almost all the propagation models are enhanced form of Okumura model. It can be used for frequencies up to $3000 \mathrm{MHz}$. The distance between transmitter and receiver can be around $100 \mathrm{~km}$ while the receiver height can be $3 \mathrm{~m}$ to $10 \mathrm{~m}$. The path loss in Okumura model can be calculated as

$$
P l(d B)=L_{f}+A_{m_{m} n}(f, d)-G\left(h_{t}\right)-G\left(h_{r}\right)-G_{A R E A}
$$

Here $L_{f}$ is the free space path loss and it is calculated by the following expression:

$$
L_{f}=-20 \log \left(\frac{\lambda}{4 \pi d_{0}}\right)
$$

While $G\left(h_{t}\right)$ and $G\left(h_{r}\right)$ are the BS antenna gain factor and receiver gain factors respectively. Their formulas are as follows:

$$
\begin{aligned}
& G\left(h_{b}\right)=20 \log \left(\frac{h_{b}}{200}\right) \\
& G\left(h_{r}\right)=10 \log \left(\frac{h_{r}}{3}\right)
\end{aligned}
$$

where $h_{b}$ and $h_{r}$ are the heights of base station and receiver receptively. $A_{m, n}(f, d)$ is called as median attenuation factor. Different curves for median attenuation factor are used depending on the frequency and the distance between the transmitter and receiver. The area gain $G_{A R E A}$ depends on the area being used and its graph along with median attenuation factor is depicted in Figure 1 [9].

\subsection{Cost-231Hata Propagation Model}

COST-231 Hata model is also known as COST Hata model. It is the extension of Hata model [6] and it can be used for the frequencies up to $2000 \mathrm{MHz}$. The expression for median path loss, PLU, in urban areas is given by

$$
\begin{gathered}
P L(d D)=46.3+33.9 \log (f)-13.02 \log \left(h_{b}\right)-\alpha\left(h_{r}\right)+\left[44.9-6.55 \log \left(h_{b}\right)\right] . \\
\log (d)+c
\end{gathered}
$$

Here, $f$ represents the frequency in $\mathrm{MHz}, \mathrm{d}$ denotes the distance between the transmitter \& receiver, $h_{b} \& h_{r}$ the correction factors for base station height and receiver height respectively. The parameter $c$ is zero for suburban \& rural environments while it has a value of 3 for urban area. The function $a\left(h_{r}\right)$ for urban area is defined as:

$$
\alpha\left(h_{m}\right)=3.2\left(\log \left(11.75 h_{m}\right)\right)^{2}-4.97
$$

and for rural \& suburban areas its is as follows:

$$
a\left(h_{r}\right)=\left(1.1 \log (f)-0.7 h_{r}-(1.58 f-0.8)\right.
$$




\subsection{COST-231 Walfisch-Ikegami Model}

COST-231 Walfisch-Ikegami model is an extension of COST Hata model [6], [7]. It can be used for frequencies above $2000 \mathrm{MHz}$. When there is Line of Site (LOS) between the transmitter \& receiver the path loss is given by the following formula:

$$
P L=42.64+26 \log (d)+20 \log (f)
$$

While in Non-Line of Sight (NLOS) conditions, path loss is given as:

$$
P L=L_{0}+L_{R T S}+L_{M S D}
$$

where $L_{O}$ is the attenuation in free-space and is described as:

$$
\text { Lo }=32.45+20 \log (d)+20 \log (f)
$$

$L_{R T S}$ represents diffraction from rooftop to street, and is defined as:

$$
L_{\text {RTS }}=-16.9-10 \log (w)+10 \log (f)+20 \log \left(h_{b}-h_{p}\right)+L_{\text {ori }}
$$

Here $L_{O R I}$ is a function of the orientation of the antenna relative to the street $a$ (in degrees) and is defined as:

$$
L_{o r i}=\left\{\begin{array}{cc}
-10+0.354 a & \text { for } 0<a<35 \\
2.5+0.075(a-35) & \text { for } 35<a<55 \\
4-0.114(a-55) & \text { for } 55<a<90
\end{array}\right.
$$

$L_{M S D}$ represents diffraction loss due to multiple obstacles and is specified as:

$$
L_{M S D}=L_{B S H}+k_{A}+k_{D} \log (d)+k_{F} \log (f)-9 \log \left(s_{b}\right)
$$

Where

$$
\begin{gathered}
L_{B S H}=\left\{\begin{array}{rr}
-18 \log \left(1+h_{t}-h_{b}\right) & \text { for } h_{t}>h_{b} \\
54+0.8\left(h_{t}-h_{b}\right) 2 d & \text { for } h_{t} \leq h_{b} \\
\text { and } \mathrm{d}<0.5 \mathrm{~km}
\end{array}\right. \\
k_{A}= \begin{cases}54 & \text { for } h_{t}>h_{b} \\
54+0.8\left(h_{t}-h_{b}\right) & \text { for } h_{t} \leq h_{b} \\
\text { and } \mathrm{d}>0.5 \mathrm{~km}\end{cases} \\
k_{D}- \begin{cases}18+15\left(\frac{h_{t}-h_{b}}{h_{b}}\right) & \text { for } \quad h_{t}>h_{b} \\
18 & \text { for } h_{t} \leq h_{b}\end{cases} \\
k_{F}=-4+k\left(\frac{f}{924}\right)
\end{gathered}
$$

Here, $k=0.7$ for suburban centers and 1.5 for metropolitan centers. 


\subsection{Ericsson 9999 Model}

This model is implemented by Ericsson as an extension of the Hata model [2], [11]. Hata model is used for frequencies up to $1900 \mathrm{MHz}$. In this model, we can adjust the parameters according to the given scenario. The path loss as evaluated by this model is described as:

where

$$
\begin{aligned}
P L= & a_{0}+a_{1} \log (d)+a_{2} \log \left(h_{b}\right)+a_{3} \log \left(h_{b}\right) \log (d) \\
& -3.2(\log (11.75))^{2}+g(f)
\end{aligned}
$$

$$
g(f)-44.49 \log (f)-4.78\left((\log (f))^{2}\right.
$$

The values of $a_{0}, a_{1}, a_{2}$ and $a_{3}$ are constant but they can be changed according to the scenario (environment). The defaults values given by the Ericsson model are $a_{0}=36.2, a_{1}=30.2, a_{2}=12.0$ and $a_{3}=0.1$. The parameter $f$ represents the frequency.

\section{SURVEY OF RELATED WORK}

LTE is well positioned to meet the requirements of next-generation mobile networks for existing 3GPP operators. It will enable operators to offer high performance, mass market mobile broadband services, through a combination of high bit-rates and system throughput, in both the uplink and downlink and with low latency [1]. A comprehensive set of propagation measurements taken at $3.5 \mathrm{GHz}$ in Cambridge, UK is used to validate the applicability of the three models mentioned previously for rural, suburban and urban environments. The results show that in general the SUI and the COST-231 Hata model over-predict the path loss in all environments. The ECC-33 model shows the best results, especially in urban environments [2]. They comparison of propagation models is also being done in [9] \& [10].

\section{Problem Statement and Main Contribution}

Our research question is to find out the radio propagation model which will give us the least path loss in a particular terrain. The main problem is that LTE is using $1900 \mathrm{MHz}$ and $2100 \mathrm{MHz}$ frequency bands in different regions of the world. In some regions, frequencies of $700 \mathrm{MHz}, 1800$ $\mathrm{MHz}$ and $2600 \mathrm{MHz}$ are also considered for LTE. For these frequency bands, many different radio propagation models are available that can be used in different terrains like urban, dense urban, suburban, rural etc. We will make a comparison between different radio propagation models and find out the model that is best suitable in a particular terrain. The comparison is made on the basis of path loss, antenna height and transmission frequency.

\section{Problem Solution}

In our simulation, two different operating frequencies $1900 \mathrm{MHz} \& 2100 \mathrm{MHz}$ are used. The average building height is fixed to $15 \mathrm{~m}$ while the building to building distance is $50 \mathrm{~m}$ and street width is $25 \mathrm{~m}$. All the remaining parameters used in our simulations are described in Table 2.

Almost all the propagation models are available to be used both in LOS \& NLOS environments. In our simulations, to make the scenario more practical, NLOS is used in urban, suburban \& rural conditions. But LOS condition is being considered for rural area in COST 231 W-I model because it did not provide any specific parameters for rural area [10].

The empirical formulas of path loss calculation as described in the earlier section are used and the path loss is plotted against the distance for different frequencies \& different BS heights. Figure 2 \& Figure 3 shows the path loss for SUI model for $1900 \mathrm{MHz} \& 2100 \mathrm{MHz}$ respectively. Similarly, Figure 4 \& Figure 5 are for Okumura model for $1900 \mathrm{MHz} \& 2100 \mathrm{MHz}$ respectively. In Figure 6, the path loss for COST 231 Hata model for $1900 \mathrm{MHz}$ is shown. In Figure 7 \& Figure 8, path loss for COST Walfisch-Ikegami Model is depicted for the same two frequencies. 
International Journal of Next-Generation Networks (IJNGN) Vol.3, No.3, September 2011

Figure 9 \& Figure 10 represents the path loss for Ericsson 9999 model.

Table 2: Simulation parameters

\begin{tabular}{|c|c|}
\hline Parameters & Values \\
\hline Base station transmitter power & $43 \mathrm{dBm}$ \\
\hline Mobile transmitter power & $30 \mathrm{dBm}$ \\
\hline Transmitter antenna height & $\begin{array}{c}30 \mathrm{~m} \& 80 \mathrm{~m} \text { in urban, suburban and rural } \\
\text { area }\end{array}$ \\
\hline Receiver antenna height & $3 \mathrm{~m}$ \\
\hline Operating frequency & $1900 \mathrm{MHz} \& 2100 \mathrm{MHz}$ \\
\hline Distance between Tx \& Rx & $5 \mathrm{~km}$ \\
\hline Building to building distance & $50 \mathrm{~m}$ \\
\hline Average building height & $15 \mathrm{~m}$ \\
\hline Street width & $25 \mathrm{~m}$ \\
\hline Street orientation angle & $30^{\circ}$ in urban and $40^{\circ}$ in suburban \\
\hline Correction for shadowing & $\begin{array}{l}8.2 \mathrm{~dB} \text { in suburban and rural and } 10.6 \mathrm{~dB} \\
\text { in urban area }\end{array}$ \\
\hline
\end{tabular}
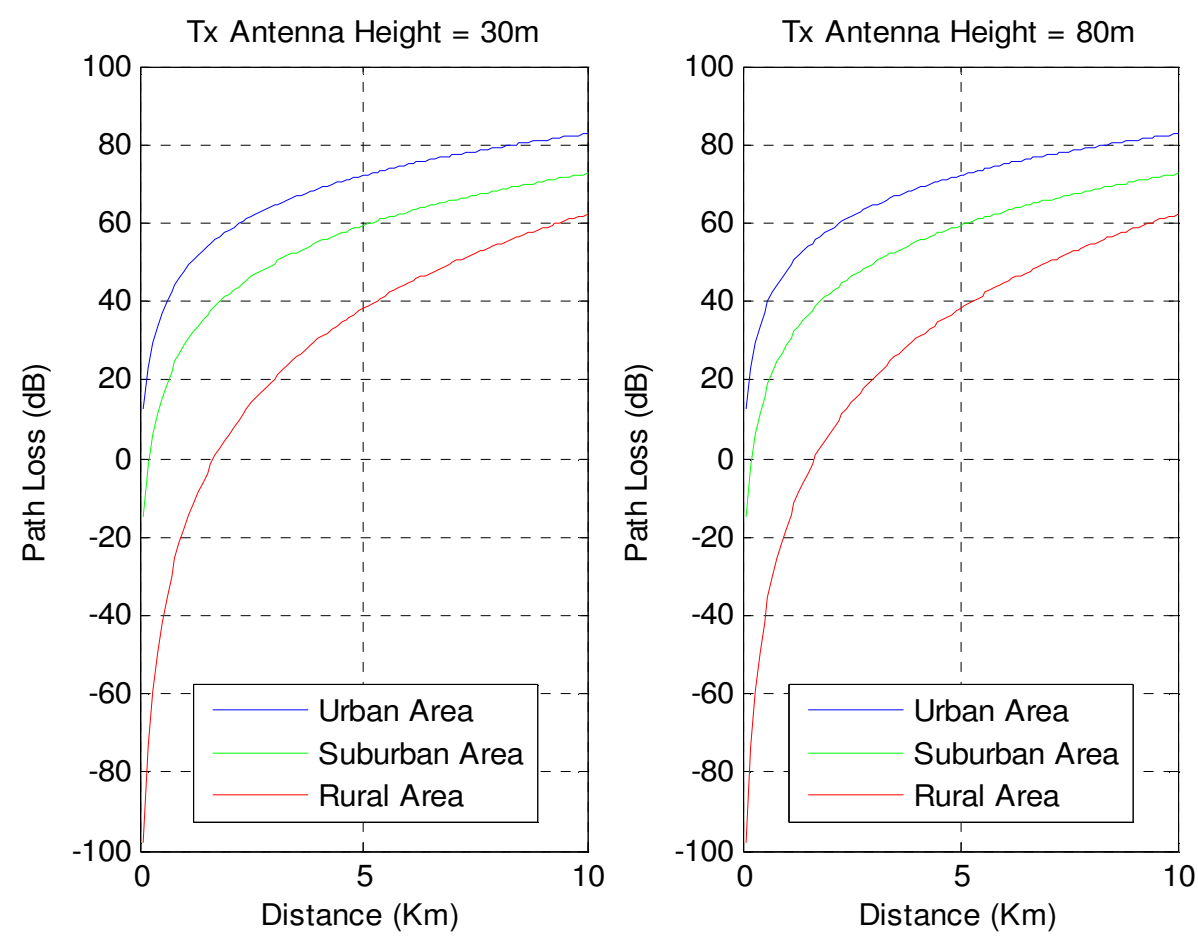

Figure 2: SUI model (for $1900 \mathrm{MHz}$ ) 
International Journal of Next-Generation Networks (IJNGN) Vol.3, No.3, September 2011
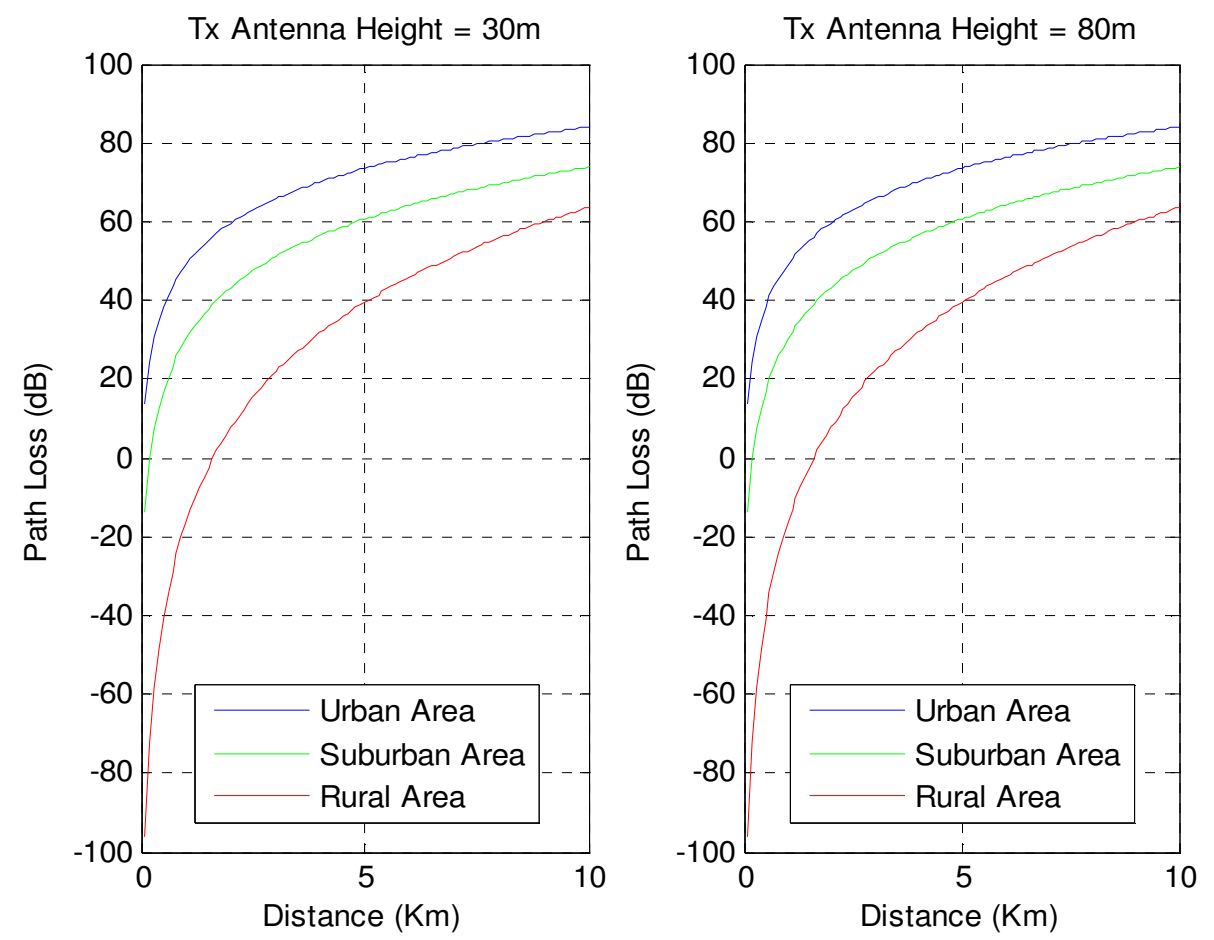

Figure 3: SUI model (for $2100 \mathrm{MHz}$ )
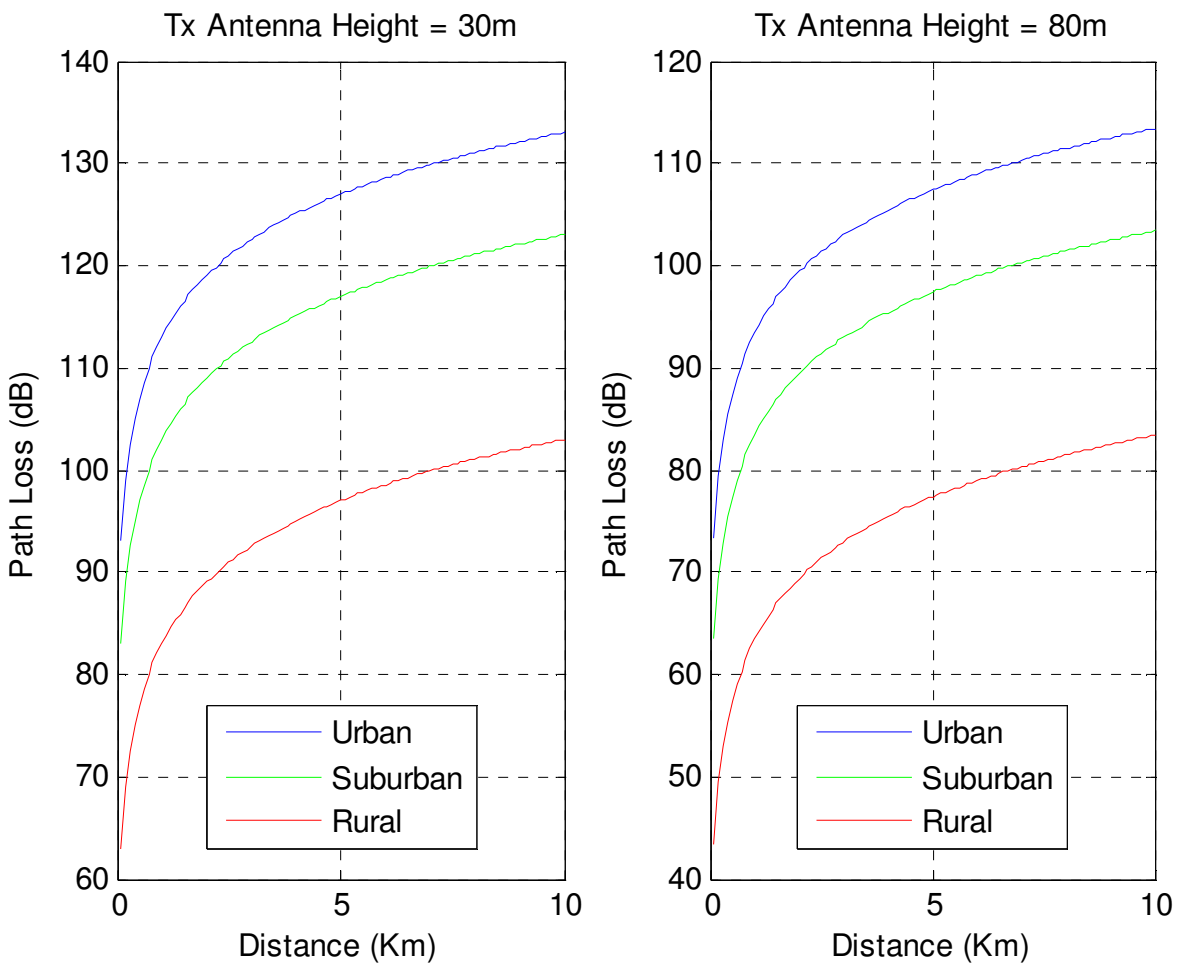

Figure 4: Okumura model (for $1900 \mathrm{MHz}$ ) 
International Journal of Next-Generation Networks (IJNGN) Vol.3, No.3, September 2011
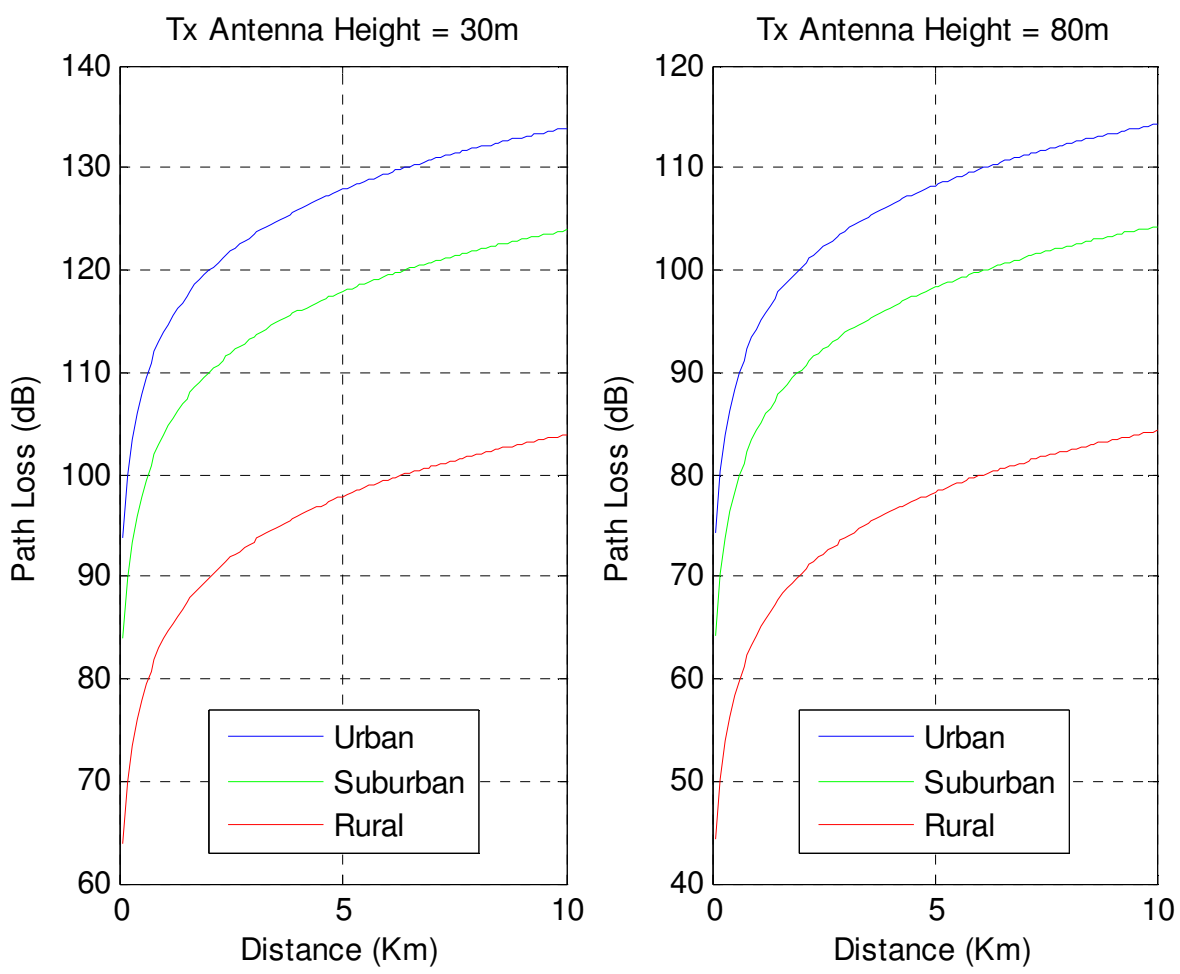

Figure 5: Okumura model (for $2100 \mathrm{MHz}$ )
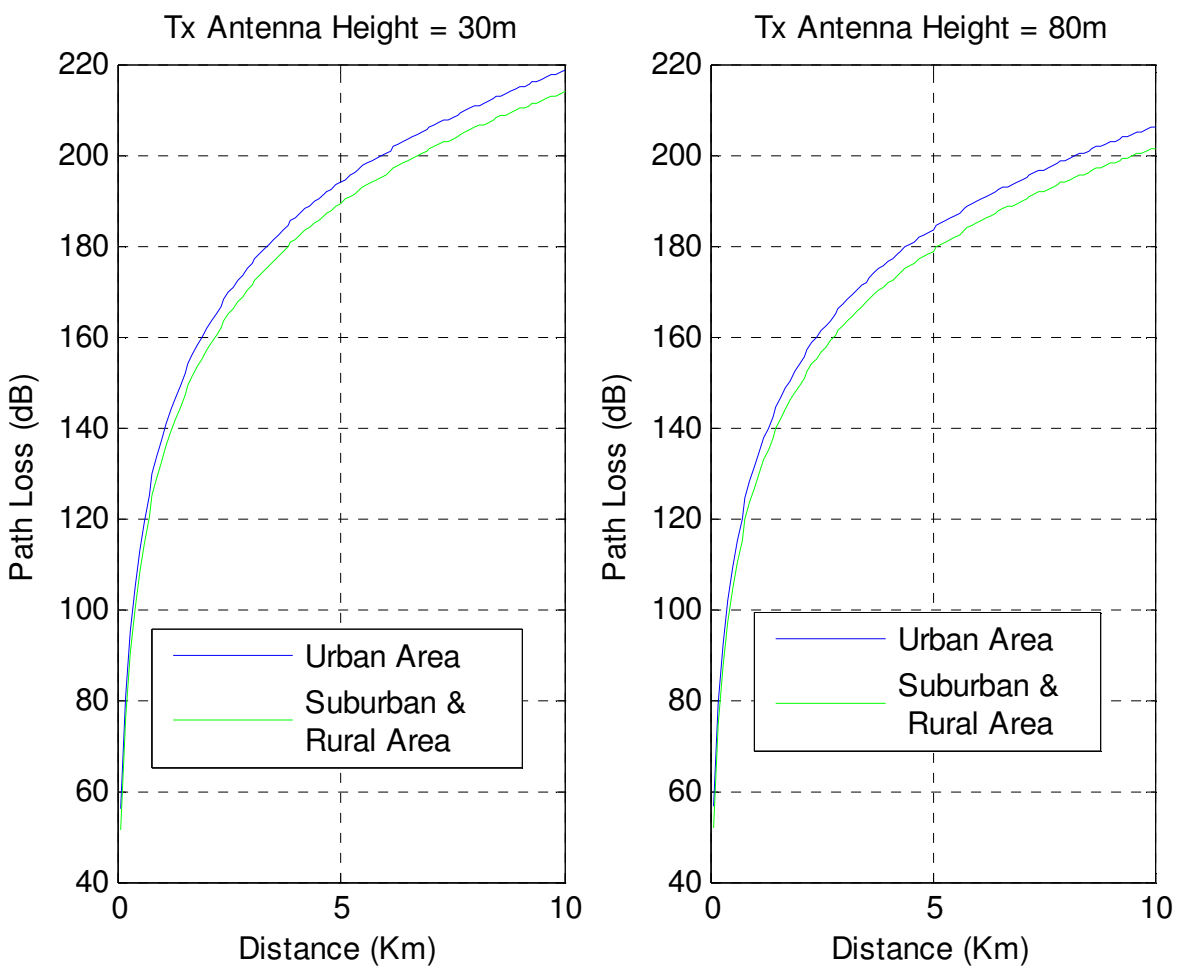

Figure 6: Hata COST 231 model (for $1900 \mathrm{MHz}$ ) 
International Journal of Next-Generation Networks (IJNGN) Vol.3, No.3, September 2011
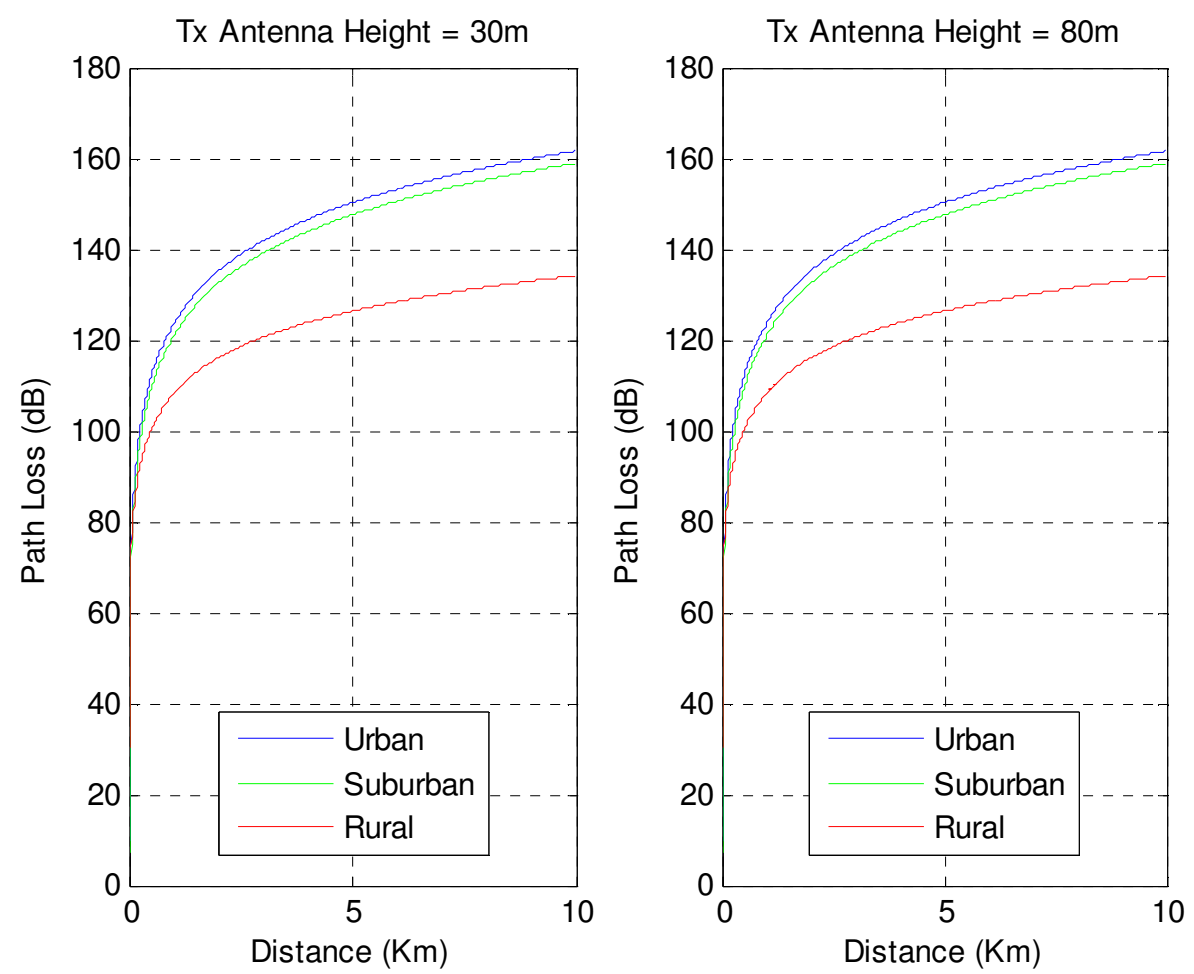

Figure 7: COST-231Walfisch-Ikegami model (for $1900 \mathrm{MHz}$ )
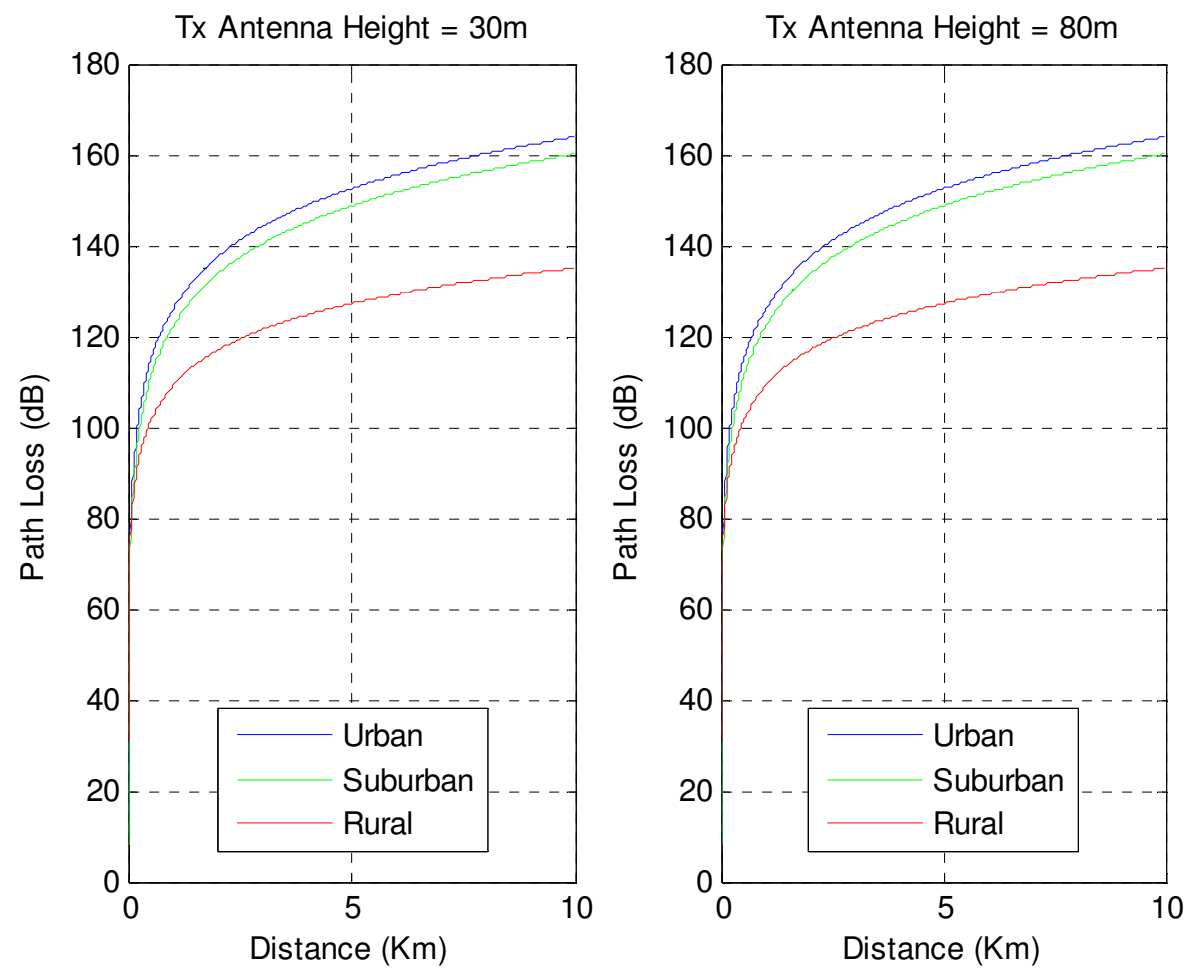

Figure 8: COST-231Walfisch-Ikegami model (for $2100 \mathrm{MHz}$ ) 
International Journal of Next-Generation Networks (IJNGN) Vol.3, No.3, September 2011
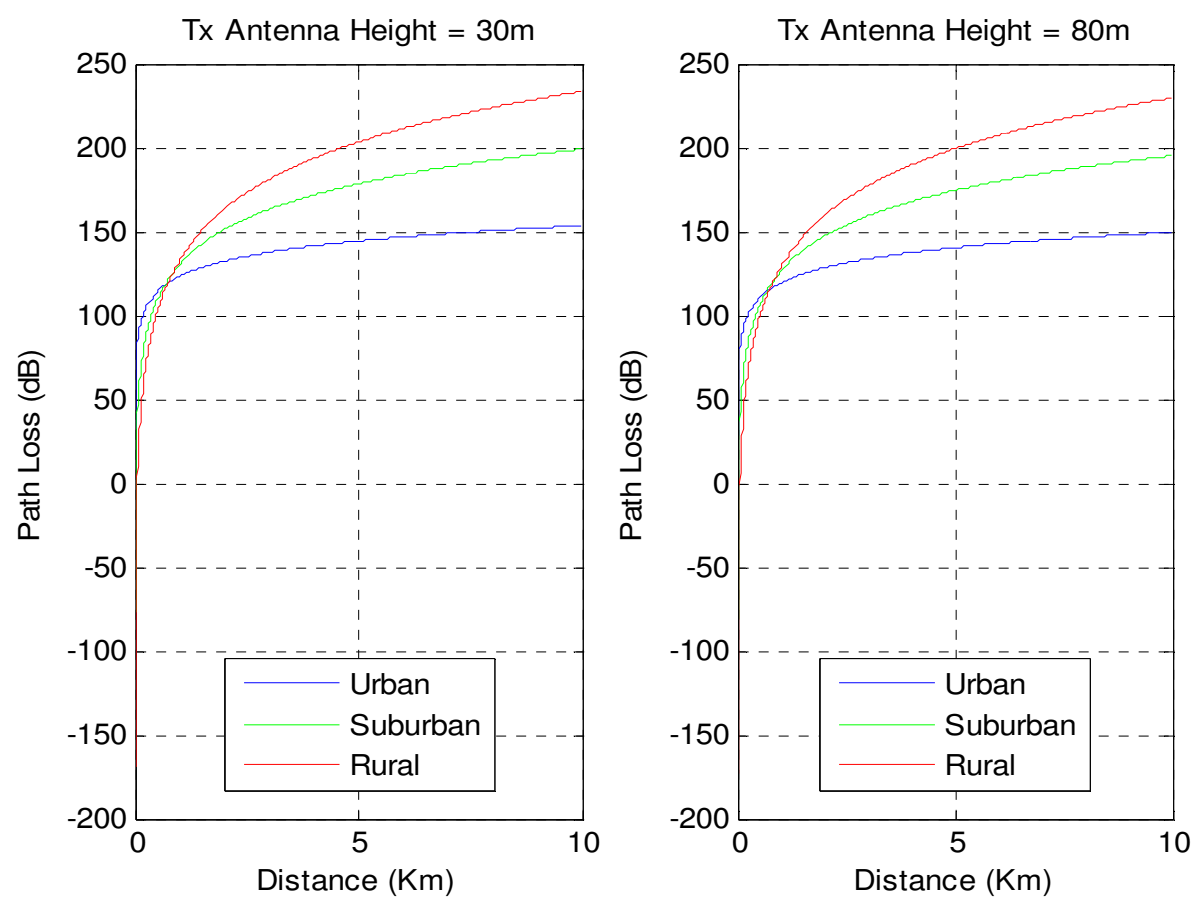

Figure 9: Ericsson 9999 model (for 1900 MHz)
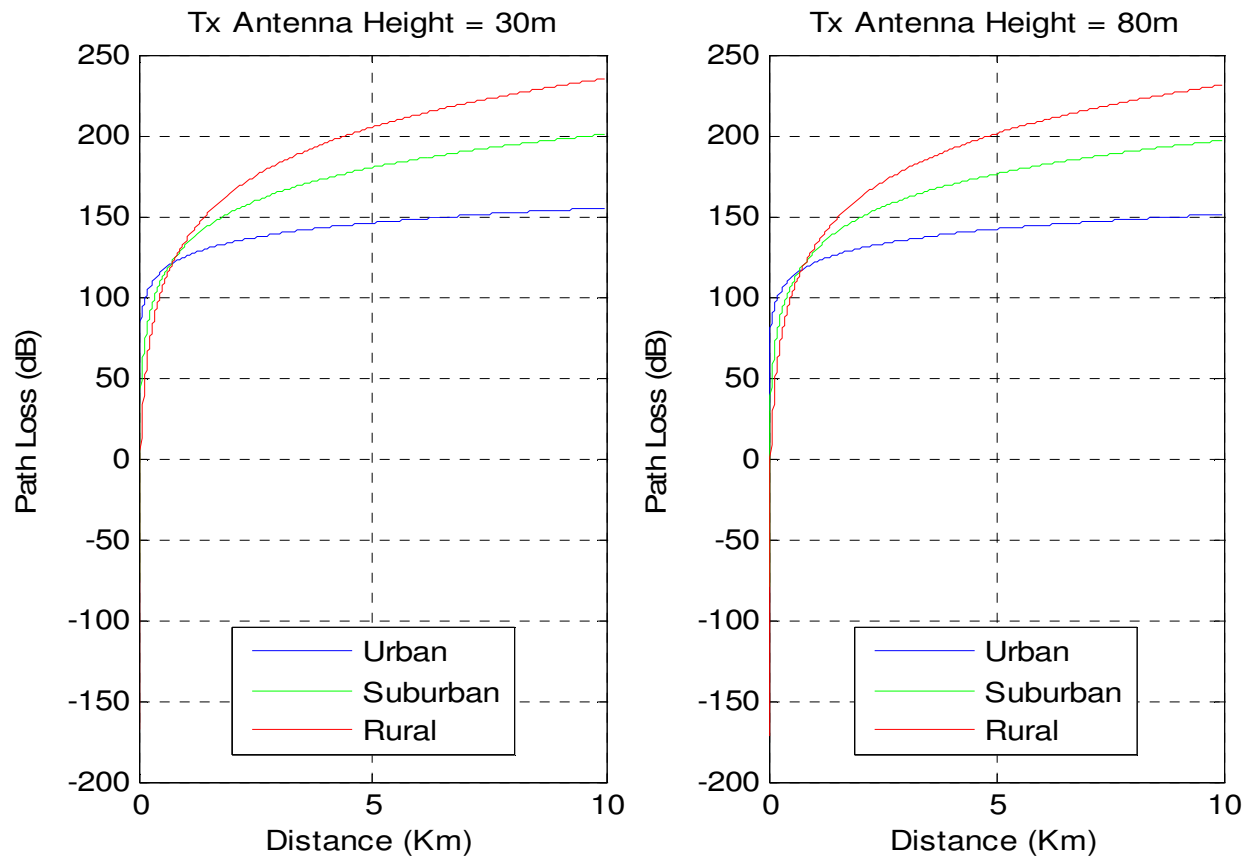

Figure 10: Ericsson 9999 model (for $2100 \mathrm{MHz}$ ) 
International Journal of Next-Generation Networks (IJNGN) Vol.3, No.3, September 2011

\section{CONCLUSION}

The accumulated path losses for all the three urban, suburban and rural terrains are shown in Table 3. It can be seen from the table that SUI model has the lowest path loss prediction (72.17 $\mathrm{dB}$ to $73.43 \mathrm{~dB}$ ) in urban environment for $1900 \mathrm{MHz} \& 2100 \mathrm{MHz}$ respectively. While, COST 231 Hata model has the highest path loss $(194.03 \mathrm{~dB})$ for $1900 \mathrm{MHz}$ in urban environment and Ericsson 999 model has the highest path loss of $145.83 \mathrm{~dB}$ for $21000 \mathrm{MHz}$.

In suburban environment, the results are the same. SUI model shows the lowest path lost of 59.83 $\mathrm{dB}$ for $1900 \mathrm{MHz} \& 60.56 \mathrm{~dB}$ for $2100 \mathrm{MHz}$. COST 231 Hata model has the highest path lost of $189.32 \mathrm{~dB}$ for $1900 \mathrm{MHz} \&$ COST Walfisch-Ikegami model has a path loss of $148.69 \mathrm{~dB}$ for $2100 \mathrm{MHz}$.

In rural environment, SUI model has the lowest path lost of $38.20 \mathrm{~dB}$ for $1900 \mathrm{MHz} \& 39.46 \mathrm{~dB}$ for $2100 \mathrm{MHz}$. COST 231 Hata model has the highest path lost of $189.32 \mathrm{~dB}$ for $1900 \mathrm{MHz} \&$ COST Walfisch-Ikegami model has a path loss of $127.21 \mathrm{~dB}$ for $2100 \mathrm{MHz}$.

It can also be seen from the Table 3 that in suburban \& rural environments, Ericsson 9999 model has more path loss than COST Walfisch-Ikegami model. Also, Ericsson 9999 model is having more path loss in suburban \& rural environments than urban environment. That is something which is unrealistic. It is due to the fact that Ericsson 9999 model was mainly designed for urban and dense urban environments and it does not provide accurate information regarding suburban \& rural areas. Hence, its values can be ignored. Another reason for using the COST WalfischIkegami model is that it describes some additional parameters which are used to describe some environmental characteristics.

The BS height has no significant impact on the path loss of SUI model in all three terrains while all the other showed variation in path loss when their BS heights are changed. Okumura model has the highest variations.

Path losses for the frequencies of $700 \mathrm{MHz}, 1800 \mathrm{MHz} \& 2600 \mathrm{MHz}$ can be calculated using the above defined path loss equations.

Table 3: Comparison of propagation models

\begin{tabular}{|l|c|c|c|c|c|c|c|}
\hline Model & $\begin{array}{c}\text { Frequency } \\
(\mathbf{M H z})\end{array}$ & $\begin{array}{c}\text { Distance } \\
(\mathbf{k m})\end{array}$ & $\begin{array}{c}\text { BS Height } \\
(\mathbf{m})\end{array}$ & $\begin{array}{c}\text { Receiver } \\
\text { Height } \\
(\mathbf{m})\end{array}$ & $\begin{array}{c}\text { Urban } \\
\text { Path } \\
\text { Loss } \\
(\mathbf{d B})\end{array}$ & $\begin{array}{c}\text { Suburban } \\
\text { Path Loss } \\
(\mathbf{d B})\end{array}$ & $\begin{array}{c}\text { Rural } \\
\text { Path } \\
\text { Loss } \\
(\mathbf{d B})\end{array}$ \\
\hline SUI & 1900 & 5 & 30 & 3 & 72.17 & 59.83 & 38.20 \\
\hline SUI & 1900 & 5 & 80 & 3 & 72.17 & 59.83 & 38.24 \\
\hline SUI & 2100 & 5 & 30 & 3 & 73.43 & 60.56 & 39.46 \\
\hline SUI & 2100 & 5 & 80 & 3 & 73.43 & 60.56 & 39.46 \\
\hline Okumura & 1900 & 5 & 30 & 3 & 126.99 & 116.99 & 96.99 \\
\hline Okumura & 1900 & 5 & 80 & 3 & 107.37 & 97.37 & 77.37 \\
\hline Okumura & 2100 & 5 & 30 & 3 & 127.86 & 117.86 & 97.86 \\
\hline Okumura & 2100 & 5 & 80 & 3 & 107.34 & 98.24 & 78.24 \\
\hline Ericsson & 1900 & 5 & 30 & 3 & 144.31 & 178.38 & 203.26 \\
\hline Ericsson & 1900 & 5 & 80 & 3 & 140.36 & 174.43 & 199.31 \\
\hline Ericsson & 2100 & 5 & 30 & 3 & 145.83 & 179.90 & 204.79 \\
\hline
\end{tabular}


International Journal of Next-Generation Networks (IJNGN) Vol.3, No.3, September 2011

\begin{tabular}{|l|c|c|c|c|c|c|c|}
\hline Ericsson & 2100 & 5 & 80 & 3 & 141.86 & 175.95 & 200.83 \\
\hline $\begin{array}{l}\text { COST } \\
231\end{array}$ & 1900 & 5 & 30 & 3 & 194.03 & 189.32 & 189.32 \\
\hline $\begin{array}{l}\text { COST } \\
231\end{array}$ & 1900 & 5 & 80 & 3 & 183.66 & 178.94 & 178.94 \\
\hline $\begin{array}{l}\text { Walfisch- } \\
\text { Ikegami }\end{array}$ & 1900 & 5 & 30 & 3 & 150.20 & 147.51 & 126.35 \\
\hline $\begin{array}{l}\text { Walfisch- } \\
\text { Ikegami }\end{array}$ & 1900 & 5 & 80 & 3 & 150.20 & 147.51 & 126.35 \\
\hline $\begin{array}{l}\text { Walfisch- } \\
\text { Ikegami }\end{array}$ & 2100 & 5 & 30 & 3 & 152.47 & 148.69 & 127.21 \\
\hline $\begin{array}{l}\text { Walfisch- } \\
\text { Ikegami }\end{array}$ & 2100 & 5 & 80 & 3 & 152.47 & 148.69 & 127.21 \\
\hline
\end{tabular}

\section{REFERENCES}

[1] LTE an Introduction, White paper, Ericsson AB, 2009.

[2] Josip Milanovic, Rimac-Drlje S, Bejuk K, "Comparison of propagation model accuracy for WiMAX on 3.5GHz," 14th IEEE International conference on electronic circuits and systems, Morocco, pp. 111-114. 2007.

[3] V.S. Abhayawardhana, I.J. Wassel, D. Crosby, M.P. Sellers, M.G. Brown, "Comparison of empirical propagation path loss models for fixed wireless access systems," 61th IEEE Technology Conference, Stockholm, pp. 73-77, 2005.

[4] Okumura, Y. a kol, "Field Strength and its Variability in VHF and UHF Land-Mobile Radio Service”, Rev. Elec. Comm. Lab, No.9-10, pp. 825 - 873, 1968.

[5] Hata, M, "Empirical Formula for Propagation Loss in Land Mobile Radio Services", IEEE Trans. Vehicular Technology, VT-29, pp. 317 - 325, 1980.

[6] COST Action 231, "Digital mobile radio towards future generation systems, final report", tech. rep., European Communities, EUR 18957, 1999.

[7] Amarasinghe K.C., Peiris K.G.A.B., Thelisinghe L.A.D.M.D., Warnakulasuriya G.M., and Samarasinghe A.T.L.K "', Fourth International Conference on Industrial and Information Systems, ICIIS 2009, 28 - 31 December 2009, Sri Lanka.

[8] Simic I. lgor, Stanic I., and Zrnic B., "Minimax LS Algorithm for Automatic Propagation Model Tuning," Proceeding of the 9th Telecommunications Forum (TELFOR 2001), Belgrade, Nov.2001.

[9] B. Ramakrishnan, R. S. Rajesh and R. S. Shaji "An Efficient Vehicular Communication Outside the City Environments", International Journal of Next Generation Networks (IJNGN), volume 2, December 2010.

[10] M. Shahjahan, A. Q. Abdulla Hes-Shafi, "Analysis of Propagation Models for WiMAX at 3.5 GHz," MS thesis, Blekinge Institute of Technology, Karlskrona, Sweden, 2009.

[11] N. Shabbir, H. Kasihf, "Radio Resource Management in WiMAX," MS thesis, Blekinge Institute of Technology, Karlskrona, Sweden, 2009. 
International Journal of Next-Generation Networks (IJNGN) Vol.3, No.3, September 2011

[12] Khaled Elleithy and Varun Rao, "Femto Cells: Current Status and Future Directions" International Journal of Next Generation Networks (IJNGN), volume 3, March 2011.

[13] H. R. Anderson, "Fixed Broadband Wireless System Design”, John Wiley \& Co., 2003.

[14] G. E. Athanasiadou, A. R. Nix, and J. P. McGeehan, "A microcellular ray-tracing propagation model and evaluation of its narrowband and wideband predictions," IEEE Journal on Selected Areas in Communications, Wireless Communications series, vol. 18, pp. 322-335, March2000.

[15] Khaled Elleithy and Varun Rao, "Femto Cells: Current Status and Future Directions" International Journal of Next Generation Networks (IJNGN), volume 3, March 2011.

[16] V. Erceg, L. J. Greenstein, et al., "An empirically based path loss model for wireless channels in suburban environments," IEEE Journal on Selected Areas of Communications, vol. 17, pp. 1205-1211, July1999.

[17] M. A. Alim, M. M. Rahman, M. M. Hossain, A. Al-Nahid, "Analysis of Large-Scale Propagation Models for Mobile Communications in Urban Area", International Journal of Computer Science and Information Security (IJCSIS), Vol. 7, No. 1, 2010.

[18] F. D. Alotaibi and A. A. Ali, April 2008, "Tuning of lee path loss model based on recent RF measurements in $400 \mathrm{MHz}$ conducted in Riyadh city, Saudi Arabia," The Arabian Journal for Science and Engineering, Vol 33, no 1B, pp. 145-152.

[19] T.S. Rappaport, "Wireless Communications Principles and Practice", Prentice-Hall, India, 2006.

[20] Stefania Sesia,Issam Toufik, and Matthew Baker, "LTE - The UMTS Long Term Evolution - from Theory to Practice", John Wiley \& Sons, 2009, ISBN 978-0-470-69716-0.

[21] Borko Furht, Syed A. Ahson, "Long Term Evolution: 3GPP LTE Radio and Cellular Technology", Crc Press, 2009, ISBN 978-1-4200-7210-5.

\section{Authors}

Noman Shabbir was born in Lahore, Pakistan in 1985. He got his BS Computer Engineering degree from COMSATS Institute of Information Technology (CIIT), Lahore, Pakistan, in 2007 and MS Electrical Engineering (Radio Comm.) degree from Blekinge Institute of Technology, Sweden in 2009. His project on Unmanned Vehicles Arial Vehicles (UAV) got 3rd position in a National competition in 2006. He is currently working as a lecturer in the Dept. of Electrical Engineering., GC University, Lahore, Pakistan. His research interests are in the field of wireless networks and computer networks.

Muhammad Tariq Sadiq was born in Lahore, Pakistan, in 1985. He received Bachelor Degree in Electrical Engineering from COMSATS Institute of Information Technology (CIIT), Pakistan, in 2009. He is currently doing Masters Degree in Electrical Engineering with emphasis on telecommunication/ signal processing from Blekinge Institute of Technology (BTH), Karlskrona, Sweden. His research interests are in the field of cognitive radio, speech processing and wireless networks.
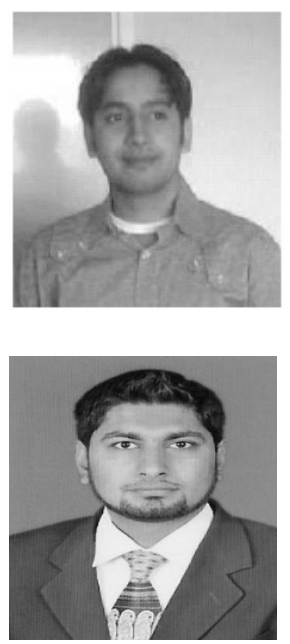
International Journal of Next-Generation Networks (IJNGN) Vol.3, No.3, September 2011

Hasnain Kashif was born in Tulamba, Distt. Khanewal, Pakistan. He has completed his BS in Computer Engineering from COMSATS Institute of Information Technology Lahore, Pakistan. He has done MSc Electrical Engineering (Radio communication) from BTH Karlskrona, Sweden. He has about two years experience in the field of telecommunication Companies in the department of Installation \& Operation, Wireless Design and also RF Department. Now he is working as a Lecturer in Department of Electrical Engineering at COMSATS Institute of Information Technology Attock, Pakistan.

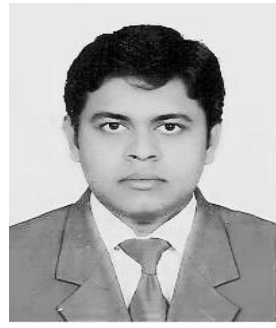

Rizwan Ullah was born in Oghi, Distt. Mansehra, Pakistan. He has completed his BS in Electronic Engineering from COMSATS Institute of Information Technology Abbotabad, Pakistan. He is currently an MSc Electrical Engineering (Communication and Radar Technology) student at CIIT Attock, Pakistan. He has about 1.5 years experience as a Lab Engineer in Department of Electrical Engineering at COMSATS Institute of Information Technology Attock, Pakistan.

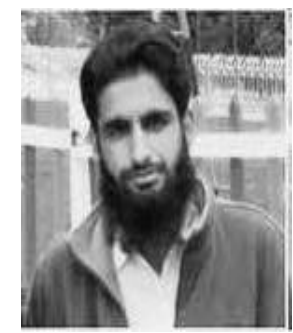

